\title{
Managing the complexity of environmental assessments of complex industrial systems with a Lean 6 Sigma approach
}

\author{
François Cluzel ${ }^{1 *}$, Bernard Yannou ${ }^{1}$, Daniel Afonso ${ }^{2}$, Yann Leroy $^{1}$, \\ Dominique Millet ${ }^{3}$ and Dominique Pareau ${ }^{4}$ \\ ${ }^{1}$ Ecole Centrale Paris, Laboratoire Genie Industriel, Chatenay-Malabry, France \\ ${ }^{2}$ CUBIK Partners, Paris, France \\ ${ }^{3}$ SUPMECA Toulon, LISMMA, Toulon, France \\ ${ }^{4}$ Ecole Centrale Paris, Laboratoire de Génie des Procédés et Matériaux, Chatenay-Malabry, \\ France
}

\begin{abstract}
The integration of environmental concerns into the product design process has highlighted a new problem that arises when confronted with complex systems. Indeed environmental assessment methodologies like Life Cycle Assessment (LCA) become in this case particularly heavy to implement. Considering aluminium electrolysis substations as a complex industrial system, we propose a new eco-design methodology based on a Lean Six Sigma approach. Including the environmental parameter as the fourth dimension of the Quality, Costs, Time triangle this methodology has the advantage to cover and systematize the entire eco-design process. It answers to most of the limits raised in our study and allows managing a part of the complexity that appears in particular during the goal and scope definition and the inventory phases of LCA. An application of aluminium electrolysis substations is mentioned.
\end{abstract}

Keywords: eco-design, Life Cycle Assessment (LCA), Lean Six Sigma, complex industrial system, electrical substation.

\section{Introduction}

Eco-design has become a major concern for many large companies in the last decade. It has first interested $B$ to $C$ firms for their consumer goods, but B to B firms now feel concerned too. Even if this growing awareness is not independent from the recent environmental regulations (for example the WEEE [1] and RoHS [2] European directives for the electrical and electronic sector), many companies attempt to go further and to propose more eco-friendly products.

In some industrial fields, the product size and complexity make the environmental studies delicate. This is particularly true for the high voltage systems provided by AREVA T\&D. It is then extremely important to own environmental tools that are able to consider such systems. Life Cycle Assessment is probably the most powerful tool in this field. However it presents some limits hard to overcome when dealing with complex industrial systems.

\footnotetext{
Contact author

E-mail: francois.cluzel@ecp.fr

Phone: +33141131328
} 
At the same time another approach has appeared in the late 90's, based on the Lean Six Sigma theory. We called this new trend Lean \& Green (term used by the US Environment Protection Agency from these years [3]). The environmental dimension is taken into account at the same level as Quality, Cost and Time.

We propose in this paper to make the link between Lean Six Sigma and Life Cycle Assessment, and more globally eco-design. Thus we propose a meta-methodology based on a DMAIC approach (Define, Measure, Analyze, Improve, and Control) that covers the entire eco-design process. This methodology ensures the continuity of the project too. It is particularly adapted to complex industrial systems.

We first describe the problem from statements stemming from an industrial case study. The second part is devoted to the existing eco-design process with a focus on Life Cycle Assessment. This introduces a study of the limits encountered for the eco-design of complex industrial systems. The fifth part presents the Lean Six Sigma concepts and tools on which the meta-methodology presented in part 6 is based. We conclude on some perspectives.

\section{How to eco-design complex industrial systems?}

We describe in this first part AREVA's aluminium electrolysis substations before stating the eco-design related issues that appear. These issues will introduce the methodology proposed later in this paper.

\subsection{Aluminium electrolysis substations}

AREVA T\&D PEM (Power Electronics Massy) designs, assembles and sells in the whole world substations for the electrolysis of aluminium. These are electrical stations to convert energy from the high voltage network to energy that can be used for aluminium electrolysis, which is a particularly polluting and energy-consuming activity. An electrolysis substation is made of thousands tons of power electronics components and transformers, for a cost of several dozens of millions Euros.

An electrolysis substation is made of several groups (often 4 on Fig. 1) that are composed of a regulating transformer, a rectifier transformer and a rectifier. The groups are connected on one side to the high voltage network through an electrical substation, and on the other side to a busbar that is directly connected to the electrolysis potline. All the groups are supervised by control elements that are connected to the electrolysis pots to regulate the process. The amount of energy consumed by a recent primary aluminium plant is comparable to the amount of energy delivered by a nuclear plant unit (about $1 \mathrm{GW}$ ).

In this context, AREVA T\&D PEM wishes to minimize the environmental impacts of its products to answer to the environmental policy of the company. It also represents a way to be differentiated from the competitors.

From the current substations design, we first want to:

- Evaluate the environmental impacts through the product life cycle. We ideally want to know the substation intrinsic impact, but also the proportion of the whole aluminium plant impacts due to the substation.

- Identify design parameters/impacting factors whose variation would permit to minimize the environmental impact while preserving the other design aspects.

- Conduct the environmental improvement of the substations.

- Ensure that the results are capitalized and reusable in the future. 


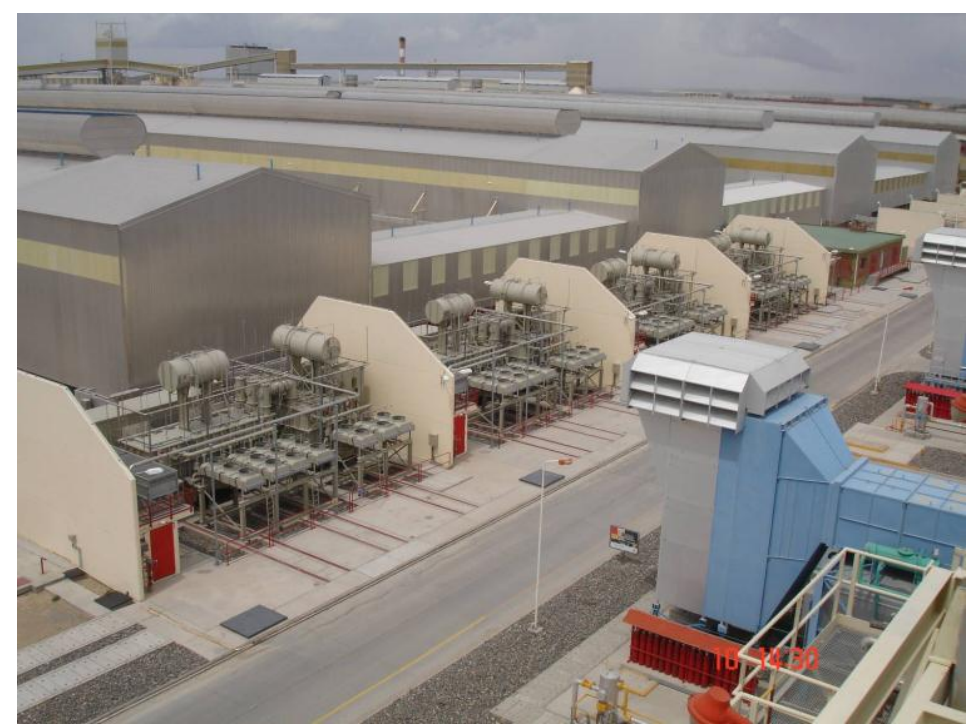

Fig. 1. Example of an AREVA T\&D aluminium electrolysis substation: ALUAR (Argentina)

\subsection{The aluminium electrolysis substation: a complex industrial system}

We consider the substations as complex industrials systems because:

- The number of subsystems and components is considerable. Some of these subsystems could themselves be considered as complex industrial systems (like transformers of rectifiers).

- The life time of the substation is really long, up to 35 or 40 years. Many uncertainties appear for the use and end-of-life phases. No end-of-life scenario is clearly known.

- The substation is only a part of the aluminium plant. Their processes are closely connected and interdependent.

It is then easy to understand that the complexity of the considered system makes the study delicate. The question is now: how to eco-design such a complex system? How to apprehend the complexity through the entire life cycle?

\section{LCA-based eco-design}

This part describes the eco-design process based on Life Cycle Assessment (LCA), which is a common approach in many large companies.

\subsection{Eco-design process}

Standard ISO/TR 14062 [4] about the integration of environmental aspects into product design and development proposes guidelines to introduce eco-design in the design process. It considers four aspects:

- Strategic considerations: the company has to define its own environmental policy, which will directly influence the competitors, customers, suppliers, investors, and more globally all the stakeholders. This policy should promote in particular an early integration of eco-design in the design process.

- Management considerations: the commitment of the top management is essential to support the integration of eco-design. Suitable resources and proactive and multidisciplinary approaches are necessary to reach significant results. 
- Product considerations: the integration of environmental considerations must occur upstream from the design process. All life cycle phases have to be considered to identify the most relevant impacts on the environment. The main objectives are the saving of resources and energy, the promotion of recycling, and more globally the prevention of pollutions and wastes.

- Product design and development process: it is important to consider environmental aspects through the various stages of the product design and development process. ISO/TR 14062 [4] describes the possible actions related to each stage: planning, conceptual design, detailed design, testing prototype, production/market launch and product review.

\subsection{Life Cycle Assessment}

One of the currently most used tools in eco-design is Life Cycle Assessment (LCA). According to ISO 14040, Life Cycle Assessment (LCA) is an evaluation tool that "addresses the environmental aspects and potential environmental impacts [...] throughout a product's life cycle from raw materials acquisition trough production, use, end-of-life treatment, recycling and final disposal (i.e. cradle-tograve)" [5].

LCA can be integrated into product design and development process at the early stages, but the assessment has to be based on existing products [6]. Despite this consideration, it is commonly considered as a powerful tool. As it is supported by international standards (ISO 14040 [5] and ISO 14044 [7]), LCA is also useful for environmental communication. LCA counts four phases:

- Goal and scope definition: its goal is to detail the objectives of the study and its field of application, in particular the system boundaries and the functional unit ("quantified performance of a product system for use as a reference unit" [5]).

- Life cycle inventory analysis: the system is divided in elementary flows that permit to identify the system inputs and outputs. This assessment of the materials and energies is called Life Cycle Inventory.

- Life cycle impact assessment: this third phase evaluates the potential environmental impacts using the inventory results. These impacts are processed with specific environmental impact categories and category indicators.

- Life cycle interpretation: the date of the previous stages are combined and analyzed to deliver consistent results according to the goal and scope. The limitations and recommendations are clarified too.

\section{Limits of the current eco-design approach}

Once we have explained the LCA-based eco-design process, we now propose to study the limits of the eco-design process and LCA for complex systems like ours.

\subsection{Technical LCA limits}

The current eco-design limits, in particular for LCA are a recurrent discussion topic. Reap [8, 9] gave a list of LCA problems by phase. We consider in this part some of these problems.

The boundary selection is hard to manage for complex industrial systems because the high number of subsystems and the interactions with surrounding systems make the boundaries fuzzy. For the same reasons, it is hard to allocate "the environmental burdens of a multi-functional process amongst its functions or products" [8]. In particular the distinction between the intrinsic environmental impacts of a product sub-system and the impacts of the whole system specifically due to the considered subsystem is not clearly made. 
Another problem concerns the inventory data granularity to choose, and more globally the data availability and quality. This problem is also taken into account by Leroy [10].

The last problems raised by Reap that interest us deal with the spatial and temporal dimensions: how to consider local data and local environmental impacts? Which information is necessary to include these elements in the study? Moreover how to know the temporal evolution of the site? We clearly need to manage the uncertainties about spatial and temporal dimensions to obtain significant results.

These technical problems are well-known by LCA practitioners. We do not pretend to solve them, but we look for a methodology that will help us to systematically consider them.

\subsection{Overall LCA and eco-design limits}

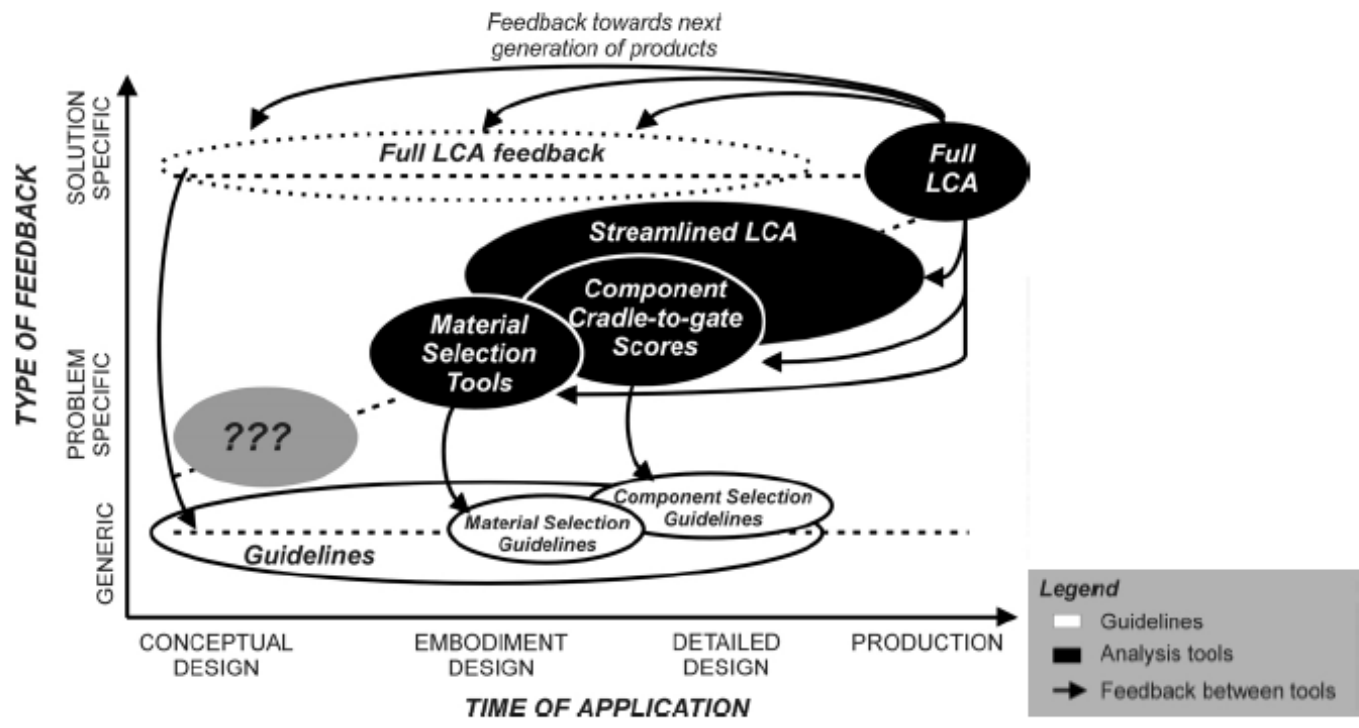

Fig. 2. Categorization of holistic eco-design tools according to type of feedback and time of application (from [11])

Except those technical limits, other problems of the eco-design process management should be considered in our study.

The first one is that LCA is an evaluation tool and not an improvement tool. It is then only the first stage of an eco-design process (see Fig. 2 [11]). Fig. 2 is also interesting because if shows that LCA is able to feed environmental improvement tools but it needs to be based on an existing product. It is not adapted for a new product design [6].

Furthermore ISO/TR 14062 [4] specifies the need of a multi-disciplinary team all along the eco-design process. But it does not precise how to build the team. The eco-design process is globally defined, but neither standardized nor systematic deliverables and milestones exist.

Finally there is no clear way to include in the study the customer requirements that will orient the decisions all along the process.

\subsection{Methodology requirements}

According to the previous parts, we need to define a methodology:

- That is able to systematically consider the technical LCA limits concerning complex industrial systems, 
- That can be declined on different systems and subsystems levels,

- That consider a reference product to improve,

- That supports ISO standards about LCA,

- That covers both the environmental evaluation and improvement phases,

- That offers a rigorous framework with precise milestones and deliverables,

- And that is able to take into account customer requirements.

\section{About Lean Six Sigma}

Because Lean Six Sigma seems to have more formalized high-level problem-setting and problem solving procedures, we consider this approach as a rigorous framework that can support the ecodesign process. In this fifth part the main concepts of Lean Six Sigma are explained to introduce the new methodology.

\subsection{Continuous improvement and Lean Six Sigma}

Lean Six Sigma is a continuous improvement approach. This kind of approach gives competitive advantages and creates value for the stakeholders. Historically, increasing the performance of one dimension of the Quality, Cost, Time triangle meant decreasing the performance of the two other dimensions. In the continuous improvement paradigm (including Lean Six Sigma), all dimensions increase together, as shown on Fig. 3. Lean Six Sigma consists in the mix of Lean Manufacturing (no wastes) and Six Sigma (increasing quality by killing variation).

We focus in the next paragraph on the DMAIC approach (Define, Measure, Analyze, Improve, Control) that is one of the main Lean Six Sigma methodologies.

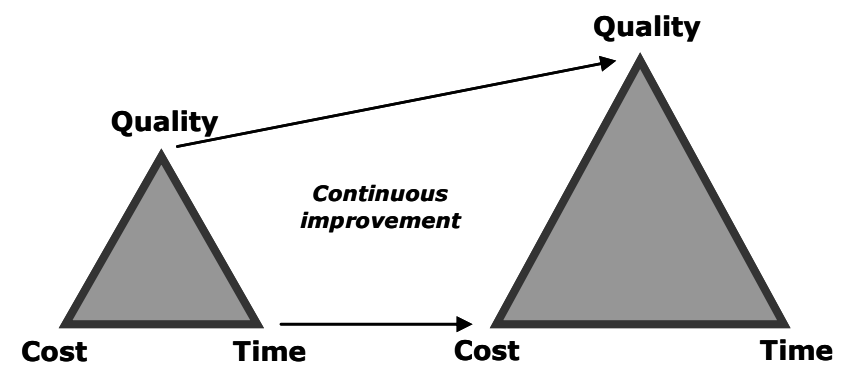

Fig. 3. Quality, Cost and Time evolution in a continuous improvement approach

\subsection{DMAIC approach}

Contrary to the PDCA (Plan, Do, Check, Act) approach that increases performance thanks to successive iterations, the DMAIC approach offers an incremental performance improvement. It is based on a rigorous methodology that is adapted to complex problems whose no solution is known. It proposes to increase performance through a structured and systematic way.

A DMAIC project is supported by a multi-disciplinary team and a project leader, who is an expert in the field. It lasts from 4 to 6 months and is formalized by precise deliverables. The DMAIC project is structured in 5 stages (see Fig.4).

\section{Define $>$ Measure $>$ Analyze Improve Control}

Fig. 4. DMAIC approach 


\subsubsection{Define}

Description: This first step in the starting point of the project and formalizes the problem thanks to a project charter.

Main deliverables: project charter, voice of the customer, team definition.

The team mission is described in the project charter that is a structured document in six stages. As for the goal and scope definition in LCA, a badly defined project charter often leads to the project failure. Fig. 5 illustrates this deliverable. The filling order is not the same as the presentation order that is adapted to communication.

1. The Five Ws (and one $H$ ) formalism is first used to describe the problem or the opportunity: Who, What, Where, When, Why, How.

2. The objectives are quantified by key indicators that cover all aspects of the problem.

3. This step is needed to identify the project perimeter and the team scope so that only the necessary and sufficient elements are included.

4. The business impact formalization permits to answer the following question: why to perform this project? This is needed to list the material and immaterial expected benefits and the necessary effort.

5. The team is selected in two stages: necessary skills identification and selection of the corresponding team members.

6. The project milestones are planned to follow the project progress.

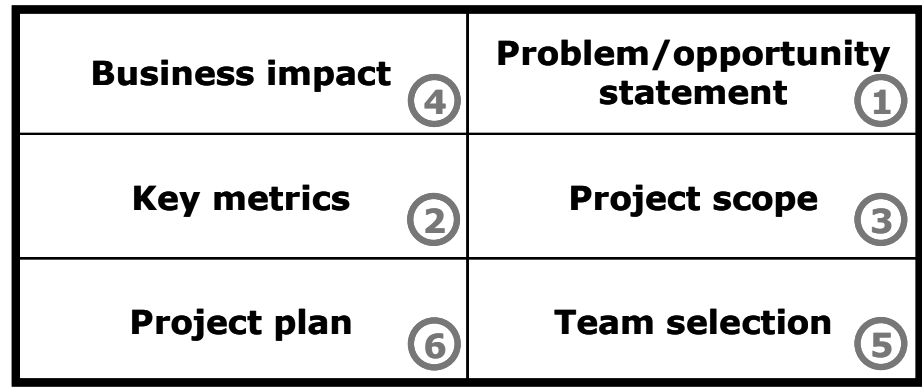

Fig. 5. Project charter

\subsubsection{Measure}

Description: This phase identifies the problem reference base and collects the data needed to know the fundamental causes.

Main deliverables: definition and identification of the keys factors, process flow diagrams, and measure system analysis.

\subsubsection{Analyze}

Description: The fundamental causes of the project are identified, that means the $20 \%$ of causes that produce $80 \%$ of the effects.

Main deliverables: identification of the potential causes, estimation of the effects on the consequences, and validation of the fundamental causes and priorisation.

\subsubsection{Improve}

Description: This phase permits to define, deploy and validate the solutions that answer to the fundamental causes. 
Main deliverables: identification of innovative solutions, validation of the solutions impact, and realization of a pilot project.

\subsubsection{Control}

Description: This last step permits to ensure the continued existence of benefits and to standardize the solutions through the company.

Main deliverables: poka yoke, procedures, training, standardization, duplication...

\subsection{Lean \& Green}

Lean \& Green is an interesting approach that appeared some years ago. We define it as a mix between Lean Six Sigma and environmental considerations in order to minimize the environmental impact of a product, service or process. Some companies or organisms propose Lean \& Green approaches.

The US Environmental Protection Agency has used this term from 2000 in a document called The Lean and Green Supply Chain [3]. The EPA has gone further since then and now proposes a structured and well-detailed approach called Lean Manufacturing and the Environment [12]. Different interesting toolkits are available:

- Lean and Environment Toolkit [13], which is oriented on the identification of the environmental wastes in a supply chain.

- Lean and Energy Toolkit [14], whose aim is to identify energy losses in an industrial process to improve performance.

Furthermore IBM has offered for several years a consulting offer called Green Sigma. "This is a new solution offering, which merges IBM's deep expertise in Lean Six Sigma with other robust green initiatives, resources and intellectual capital across the company" [15]. The Green Sigma project is divided into five stages: define key performance indicators, establish metering, deploy carbon dashboard, optimize processes and control performance

Those two Lean \& Green approaches have advantages (use of the rigorous Lean Six Sigma framework to optimize complex systems), but we consider that they stay site-oriented and are hardly applicable to products (we consider the whole product life cycle). They potentially offer powerful tools to assess the environmental quality of supply chains and organizations and, consequently, they are more oriented for environmental management systems (see ISO 14001 [16]).

Furthermore LCA is well-known and mature methodology developed for some decades but it reaches limits for complex systems. We are convinced that Lean Six Sigma is able to help us to environmentally assess industrial complex systems.

That is why we propose in the next part a Lean \& Green approach for complex product environmental assessment and improvement.

\section{Proposition of a meta-methodology}

Then the need to offer a rigorous frame to the eco-design process appears when complex systems are considered. We propose in this part to use the DMAIC approach previously described. 


\subsection{General concept}

We not only consider the three dimensions (Quality, Cost, Time) commonly used in a Lean Six Sigma approach, but also a fourth dimension, as shown on Fig. 6: Environment.

As we will see in the next paragraph, one of the main advantages of the new methodology is to cover the eco-design process form the beginning (requirements definition) to the end (environmental improvement validation). We include at the same time environmental evaluation (here, Life Cycle Assessment) and environmental improvement. That is why we call it a meta-methodology.

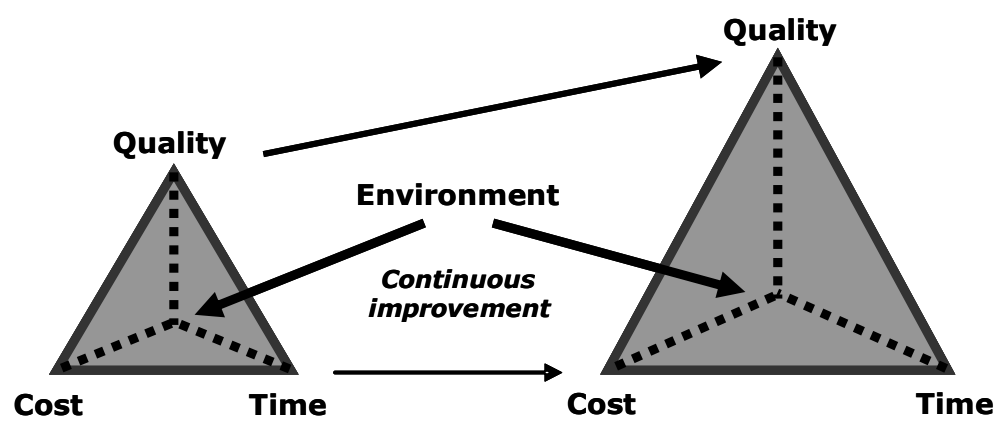

Fig. 6. Integration of the environmental dimension in the QCT triangle

This new methodology is based on DMAIC and permits to clearly formalize and systematize all the stages of the eco-design process, particularly the two first LCA phases, which appear to be the more delicate phases considering complex systems. The DMAIC approach will also allow using other Lean Six Sigma tools to improve the overall performance all along the process (for example Six Sigma statistical tools).

A question that could appear quickly is the following: why to consider a DMAIC approach instead of a DMADV (Define, Measure, Analyze, Design, Verify) approach that is oriented towards new processes design (Design for Lean Six Sigma theory)? LCA needs to work on an existing product, because it needs lots of precise data that are not available during the first phases of the new product design process [6]. So even if we consider a product development process, we work from an existing product. That is why we do not consider the DMADV approach.

\subsection{A DMAIC approach for eco-design}

A classical DMAIC process is applied on clearly identified processes starting from a supplier to a customer. In our situation, we consider that the studied process is the life cycle of the product, or a part of this life cycle. The associated suppliers and customers are all the stakeholders of the product.

\subsubsection{Define}

The first phase of the DMAIC project is clearly adapted for the Goal and Scope definition of LCA. The points 1, 2 and 3 of the project charter are easily able to integrate the ISO requirements about LCA. This document is detailed in Table 1.

Moreover the Define phase offers tools such as the Voice of Customer that will permit to connect the eco-design study on real and tangible requirements. It is really important to consider here not only the final customer, but also all the stakeholders. The team definition is another element of the Define phase that is not clearly identified in a classical eco-design project and that will permit to directly focus the right resources on the project. 
Table 1. The new project charter in line with the ISO standards dedicated to LCA

\begin{tabular}{|c|c|}
\hline $\begin{array}{l}\text { 4. Business impact } \\
\text { The material and immaterial expected benefits are listed, } \\
\text { as well as the efforts needed to reach these benefits. } \\
\text { For example, the expected benefits could be: } \\
\text { - Environment: decreasing of the environmental } \\
\text { impact on the whole lifecycle, } \\
\text { - Cost: decreasing of the Life Cycle Cost (LCC), } \\
\text { - Quality: increasing of the components quality } \\
\text { - Time: extension of the product life time. }\end{array}$ & $\begin{array}{l}\text { 1. Problem/opportunity statement } \\
\text { For example: AREVA T\&D PEM (Who?) whishes to } \\
\text { optimize the environmental impact of its aluminium } \\
\text { electrolysis substations (What?) during the design } \\
\text { process (When?). These substations are sold } \\
\text { worldwide to primary aluminium plants (Where?) to } \\
\text { convert energy form high voltage networks to energy } \\
\text { that is usable for aluminium electrolysis. The study will } \\
\text { permit to minimize the environmental impact through } \\
\text { the product life cycle while still considering the } \\
\text { technical and economical criteria (How?). It is a way } \\
\text { for AREVA T\&D PEM to answer to AREVA's } \\
\text { environmental policy and to be differentiated from the } \\
\text { competitors (Why?). }\end{array}$ \\
\hline $\begin{array}{l}\text { 2. Key metrics } \\
\text { The objectives are described according to ISO } 14040 \text { [5]: } \\
\text { - Intended application, } \\
\text { - Reasons for carrying out the study, } \\
\text { - Intended audience, } \\
\text { - Are the results intended to be used in public } \\
\text { comparative assertions? } \\
\text { The key indicators are the environmental indicators } \\
\text { chosen for the study according to the objectives and the } \\
\text { intended audience. Other indicators can be considered } \\
\text { such as technical or economical, or even social in a } \\
\text { sustainable development perspective. }\end{array}$ & $\begin{array}{l}\text { 3. Project scope } \\
\text { The expected information asked by ISO } 14040 \text { to } \\
\text { define the scope of the study is [5]: } \\
\text { - Studied product system, } \\
\text { - Functions of the product system, } \\
\text { - Functional unit, } \\
\text { - System boundary, } \\
\text { - Allocation procedures, } \\
\text { - Selected impact categories and impact } \\
\text { - Dassessment methodology, } \\
\text { - Assumptions, } \\
\text { - Limitations, } \\
\text { - Initial data quality requirements } \\
\text { - Type of critical review, if any, } \\
\text { - Type and format of the report. } \\
\text { These elements have to be detailed enough to meet } \\
\text { the DMAIC requirements. }\end{array}$ \\
\hline $\begin{array}{l}\text { 6. Project plan } \\
\text { The project milestones are defined. }\end{array}$ & $\begin{array}{l}\text { 5. Team selection } \\
\text { The members of the eco-design team are selected. }\end{array}$ \\
\hline
\end{tabular}

\subsubsection{Measure}

The second phase, Measure, includes in the new methodology the second and third LCA phases: Life Cycle Inventory and Life Cycle Impact Assessment. Those two stages actually provide the data needed to know the fundamental causes of the problem.

The flow diagram that is a key element of the inventory can be drawn up thanks to Lean Six Sigma tools like VSM (Value Stream Mapping) or SIPOC (Supplier, Input, Process, Output, and Customer).

\subsubsection{Analyze}

Thanks to the LCI and the LCIA the fundamental causes are identified in the Life Cycle Interpretation, for example by performing sensitivity and uncertainty analysis. It is the last LCA phase, and it corresponds to the Analyze phase of the DMAIC approach. 
Then the product environmental evaluation is ended. The main environmental impacts have been identified and some leads appear to improve the product; the environmental improvement phase begins.

\subsubsection{Improve}

Thanks to the LCA results and environmental improvement tools, technological solutions answering to the fundamental causes are identified.

Different environmental tools exist, such as standards, lists (guidelines, check-lists, material lists), guides or software. Lots of large companies have defined their own rules and procedures to improve the environmental impact of their product, like the materials lists. Luttropp proposes also the Ten Golden Rules in Eco-Design [17], which are generic rules to eco-design a product. They can be adapted for more specific fields.

The technical solutions can be validated by performing comparative LCA with the technologies used in the original product.

\subsubsection{Control}

In the Control phase, the new product is validated by aggregating the whole data in a comparative LCA between the old and the new design. The concerned actors then need to be trained. Finally, the environmental benefits are internally (and eventually externally) communicated to ensure the spreading of good practices.

\subsection{Meta-methodology deployment on aluminium electrolysis substations}

We now want to deploy this meta-methodology on AREVA's aluminium electrolysis substations. This project will last several months and will follow the different steps tackled in this paper.

First, the DMAIC approach for eco-design will permit to clearly set the problem, define the objectives and the working group in accordance with the ISO standards. This accordance is important to be able to communicate significant results at the end of the study to be differentiated from the competitors.

The next step will be the environmental evaluation of the substations from an existing reference product to identify the most impacting factors.

The third step will be the environmental improvement using the key factors above, and the comparison between the reference and the new product.

Finally the results will be communicated towards the stakeholders and possibly a wider audience. They will also be stored for future projects.

It is important to notice that this DMAIC process could be adapted to different levels: a global implementation as described above will allow identifying the key factors in the different life cycles phases and among the numerous subsystems.

\section{Conclusions and perspectives}

We have proposed in this paper a clear enrichment of the present standardized ISO 1404X LCA process for complex systems through the deployment of a Lean Six Sigma approach. The new proposed DMAIC project permits to comprehend the system complexity thanks to a rigorous 
framework covering the environmental evaluation (LCA) and the environmental improvement of the product.

Fig. 7 summarizes the different approaches conducting to the new DMAIC project for eco-design. We have compared the classical eco-design process to a DMAIC project stemming from the Lean Six Sigma theory. The advantages of the two methodologies have been compiled in the new one. The main contributions of Lean Six Sigma to our approach are:

- The covering of the entire eco-design process,

- The clear formalization of the problem in particular thanks to the project charter,

- The rigorous framework of the project thanks to precise milestones,

- The clear definition of the team and their role all along the project according to these milestones,

- The contribution of other Lean Six Sigma tools all along the project.

We now need to validate our approach through an application on AREVA's aluminium electrolysis substations.
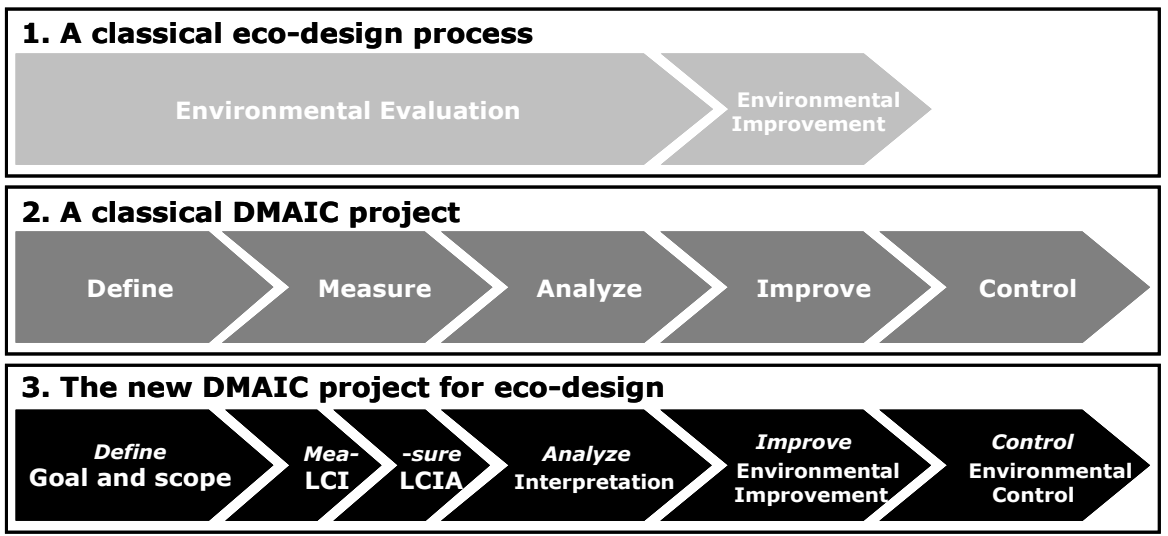

Fig. 7. The different approaches considered in the paper

Even if the proposed methodology allows managing the eco-design project for complex systems, some stages remains hard to perform. Some perspectives appear to simplify them. They could also be applied on our case study but have to be discussed before:

- The results of the PhD thesis of Yann Leroy [10] could have a great impact on our own works. Leroy has designed a methodology to make the results of LCA more reliable by working on the inventory data quality. One of his results is the possibility to identify and locate the data the most influential on the quality index. It is then possible to optimize the data collection and the allocated resources.

- It could be interesting too to adopt an approach like Analytical Target Cascading [18]. ATC allows optimizing the global system through the optimization of the subsystems and the aggregation of these results by simulation. ATC is based on a hierarchical decomposition of the system and the definition of design targets at each level (from the system to the components). This theory will be studied in more details in the next months.

\section{References}

[1] European Union, Directive 2002/96/EC of the 27 January 2003 on waste electrical and electronic equipment (WEEE), 2003. 
[2] European Union, Directive 2002/95/EC of the 27 January 2003 on the restriction of the use of certain hazardous substances in electrical and electronic equipment, 2003.

[3] US Environmental Protection Agency, "The Lean and Green Supply Chain: a practical guide for materials managers and supply chain managers to reduce costs and improve environmental performance," 2000.

[4] International Organization for Standardization, ISO/TR 14062:2002 - Environmental management - Integrating environmental aspects into product design and development, 2002.

[5] International Organization for Standardization, ISO 14040:2006 - Environmental management - Life cycle assessment - Principles and framework, 2006.

[6] D. Millet, L. Bistagnino, C. Lanzavecchia, R. Camous, and T. Poldma, "Does the potential of the use of LCA match the design team needs?," Journal of Cleaner Production, vol. 15, 2007, pp. 335-346.

[7] International Organization for Standardization, ISO 14044:2006 - Environmental management - Life cycle assessment - Requirements and guidelines, 2006.

[8] J. Reap, F. Roman, S. Duncan, and B. Bras, "A survey of unresolved problems in life cycle assessment - Part 1: goal and scope and inventory analysis," The International Journal of Life Cycle Assessment, vol. 13, Jun. 2008, pp. 290-300.

[9] J. Reap, F. Roman, S. Duncan, and B. Bras, "A survey of unresolved problems in life cycle assessment - Part 2: impact assessment and interpretation," The International Journal of Life Cycle Assessment, vol. 13, 2008, pp. 374-388.

[10] Y. Leroy, "Development of a methodology to reliable environmental decision from Life Cycle Assessment based on analysis and management of inventory data uncertainty," PhD Thesis, Ecole Nationale Supérieure d'Arts et Métiers, Chambéry, France, 2009.

[11] W. Dewulf, "A pro-active approach to ecodesign: framework and tools," PhD Thesis, Katholieke Universiteit Leuven, 2003.

[12] US Environmental Protection Agency, "Lean Manufacturing and the Environment," http://www.epa.gov/lean/leanenvironment.htm, 2009.

[13] US Environmental Protection Agency, "The Lean and Environment Toolkit," 2007.

[14] US Environmental Protection Agency, "The Lean and Energy Toolkit," 2007.

[15] IBM, "Green Sigma - How to optimise your carbon management through Green Sigma," 2009.

[16] International Organization for Standardization, ISO 14001:2004 - Environmental management systems - Requirements with guidance for use, 2004.

[17] C. Luttropp and J. Lagerstedt, "EcoDesign and The Ten Golden Rules: generic advice for merging environmental aspects into product development," Journal of Cleaner Production, vol. 14, 2006, pp. 1396-1408.

[18] H.M. Kim, N.F. Michelena, P.Y. Papalambros, and T. Jiang, "Target Cascading in Optimal System Design,” Journal of Mechanical Design, vol. 125, 2003, pp. 474-480. 